\title{
Desenvolvimento de glossário de Sinais Acadêmicos em ambiente virtual de aprendizagem do curso Letras-Libras
}

\section{Development of on-line glossary of academic signs for letras-libras course}

Resumo: O movimento de inserção dos surdos no espaço acadêmico garantido pelas legislações atuais de acessibilidade e reconhecimento de sua língua tem possibilitado avanços nas pesquisas relativas à Língua Brasileira de Sinais. Os recursos tecnológicos ampliam ainda mais as perspectivas destas pesquisas e interações entre as pessoas surdas. A Universidade Federal de Santa Catarina em convênio com mais 17 instituições de ensino públicas e com apoio do Ministério da Educação tem explorado estes recursos e o espaço conquistado para ampliar o léxico de Libras de forma responsável e consciente, especialmente nas áreas de educação e linguística. Ciente da relevância deste movimento, a Equipe de Tradução do curso de Letras-Libras vem elaborando e disponibilizando aos estudantes do curso o Glossário Letras-Libras. Devido às solicitações de intérpretes, pesquisadores e instituições, este artigo tem como objetivo apresentar a dinâmica do trabalho da equipe e as possibilidades de exploração dos recursos tecnológicos existentes.

Palavras-chave: Ambiente virtual de aprendizagem. Educação de Surdos. Glossário. Tecnologias para acessibilidade.

Abstract: The movement of insertion of the deaf in the academic space guaranteed by current legislation on accessibility and the recognition of their language has enabled advances in research on Brazilian Sign Language. The technological capabilities extend even further prospects for this research and the interactions among deaf people. The Federal University of Santa Catarina in partnership with 18 other public educational institutions and with support from the Ministry of Education has been exploring these resources and the space gained to expand the lexicon of Libras (Brazilian Sign Language) in a responsible and conscious way, especially in education and linguistics. Aware of the importance of this movement, the Translation Team of the Letras-Libras graduate course has been developing and making available to students the Glossary of Letras-Libras. Owing to requests from interpreters, researchers and institutions, this article aims to present the dynamics of the team's work and the possibilities for exploitation of existing technological resources.

Keywords: Virtual Learning Environment. Deaf Education. Glossary. Technologies for accessibility.

OLIVEIRA, Janine Soares; STUMPF, Marianne Rossi. Desenvolvimento de glossário de Sinais Acadêmicos em ambiente virtual de aprendizagem do curso Letras-Libras. Informática na Educação: teoria e prática, Porto Alegre, v. 16, n. 2, p. 217-228, jul./dez. 2013.

\section{Janine Soares Oliveira \\ Marianne Rossi Stumpf \\ Universidade Federal de Santa Catarina}

\section{Introdução}

0 número de estudantes surdos nas universidades, particulares e públicas tem aumentado no Brasil, notadamente na última década, a partir do decreto 5.626. ${ }^{1}$ Destaca-se neste fenômeno a participação da Universidade Federal de Santa Catarina - UFSC, responsável pela implantação do Curso de Letras-Libras, pioneiro para formação professores e tradutor/interpretes de Libras - Língua Brasileira de Sinais. Atualmente o curso conta com aproximadamente 1.300 estudantes alocados no campus da UFSC e nos 17 pólos das Universidades conveniadas nos diferentes estados do país.

O curso de Letras-Libras vem sendo desenvolvido sob a perspectiva de favorecer o aces-

${ }^{1}$ O decreto 5.626 de 22 de dezembro de 2005 regulamenta a Lei no 10.436, de 24 de abril de 2002, que dispõe sobre a Língua Brasileira de Sinais - Libras, e o art. 18 da Lei no 10.098, de 19 de dezembro de 2000. Disponível em http://www.planalto.gov.br/ccivil/_Ato2004-2006/2005/Decreto/D5626.htm 
so ao espaço acadêmico, prioritariamente para pessoas surdas, conforme previsto no decreto 5.626. A modalidade à distância visa à democratização desse processo de formação. Diferentes regiões do país têm a oportunidade de formar professores de Libras e Tradutores/Intérpretes de Libras na perspectiva dos próprios surdos, atuantes em diversos setores desde a concepção até o funcionamento diário do curso em uma ação conjunta do Ministério da Educação com a UFSC e os demais 17 pólos em que funciona. A saber: Universidade Federal de Santa Maria - UFSM/RS, Universidade Federal do Rio Grande do Sul - UFRGS/RS, Universidade Federal do Paraná - UFPR/PR, Universidade de São Paulo - USP/SP, Universidade Estadual de Campinas - UNICAMP/SP, Instituto Nacional de Educação de Surdos - INES/RJ, Centro Federal de Educação Tecnológica de Minas Gerais - CEFET/MG, Universidade Federal do Espírito Santo - UFES/ES, Universidade de Brasília UNB, Instituto Federal de Educação Ciência e Tecnologia - IFG/GO, Instituto Federal de Educação Ciência e Tecnologia - IFRN/RN, Universidade Federal da Grande Dourados - UFGD/ MS, Universidade do Estado do Pará - UEPA/ $P A$, Universidade Federal do Ceará - UFC/CE, Universidade Federal da Bahia - UFBA/BA, Universidade Federal de Pernambuco - UFPE/PE, Universidade Federal do Amazonas - UFAM/AM.

Para garantir o acesso e a permanência das pessoas surdas na Universidade, todos os materiais são traduzidos para Libras e disponibilizados em vídeo no ambiente virtual de aprendizagem do curso. ${ }^{2}$ Há uma equipe responsável pela tradução destes materiais em constante estudo e reavaliação para aprimoramento do trabalho. Tal demanda possibilitou mais um campo de trabalho para pessoas surdas: a tradução de materiais didáticos.

${ }^{2}$ www.libras.ufsc.br
Os tradutores/atores são pessoas surdas bilíngues - fluentes em Libras e língua portuguesa - conhecedores das realidades culturais que permeiam os falantes destas duas línguas. Sendo uma área relativamente nova da tradução, os primeiros tradutores ${ }^{3}$ precisam criar suas próprias estratégias para desenvolver esse trabalho, visto que existem especificidades da modalidade visual espacial que impedem a apropriação das estratégias já utilizadas e consolidadas para o caso das línguas orais.

Desde a abertura do curso, que teve a primeira turma iniciada em 2006, um considerável volume de materiais acadêmicos vem sendo traduzido para Libras e disponibilizado para os estudantes. O processo de tradução destes materiais gerou e continua gerando extensa lista bilíngue (Português - Libras) de verbetes específicos da área acadêmica de letras e linguística.

A tradução destes termos técnicos demanda discussão permanente da equipe, pesquisa e criação de neologismos a fim de minimizar a dificuldade dos estudantes na compreensão dos textos acadêmicos.

Como resultado deste trabalho vem sendo disponibilizado um glossário no ambiente virtual do curso Letras-Libras. O Glossário Letras- Libras é um recurso didático relevante para formação dos estudantes do curso visto que orienta sobre o significado de termos técnicos da educação de surdos e ensino de línguas apresentados em Libras, de modo que sejam inteligíveis ao público alvo, através de vídeos produzidos por tradutores/pesquisadores surdos.

Neste artigo, será destacado o desenvolvimento do Glossário Letras-Libras como ferra-

\footnotetext{
3 Neste artigo o termo 'tradutores' se refere a profissionais surdos que realizam a tradução do português escrito para a Língua Brasileira de Sinais (Libras).
} 
menta para o processo de ensino aprendizagem no ambiente virtual do curso Letras-Libras. A fim de contextualizar o leitor sobre a especificidade desta área de atuação, serão apresentados: a dinâmica de trabalho da equipe de tradução, o glossário como instrumento de apoio a aprendizagem, a metodologia de desenvolvimento do Glossário Letras-Libras, a Escrita de Sinais como importante registro (escrito) da Libras, assim como os recursos tecnológicos utilizados e as perspectivas de ampliação do trabalho.

\section{Dinâmica da equipe de tradução}

A equipe de tradução atua integrada aos laboratórios Designlab e Hiperlab ambos localizados no bloco A do Centro de Comunicação e Expressão - CCE - UFSC. Nesse espaço funciona o estúdio (Figura 1) para produção dos vídeos do ambiente virtual de aprendizagem possui fundo infinito (Figura 2), 3 refletores de luz, filmadora integrada a um computador para realizar a captura dos vídeos e acoplada em um aparelho de teleprompter (Figura 3) ligado a outro microcomputador para leitura dos arquivos que serão traduzidos.

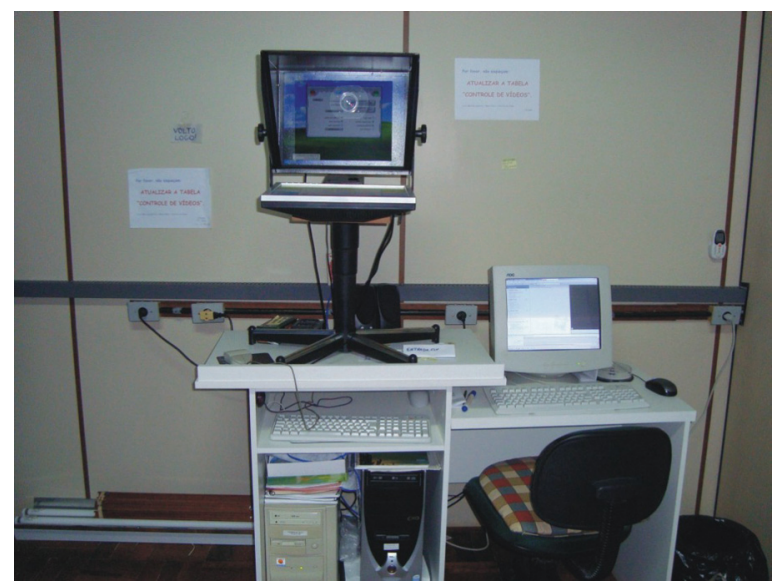

Figura 1. Equipamentos

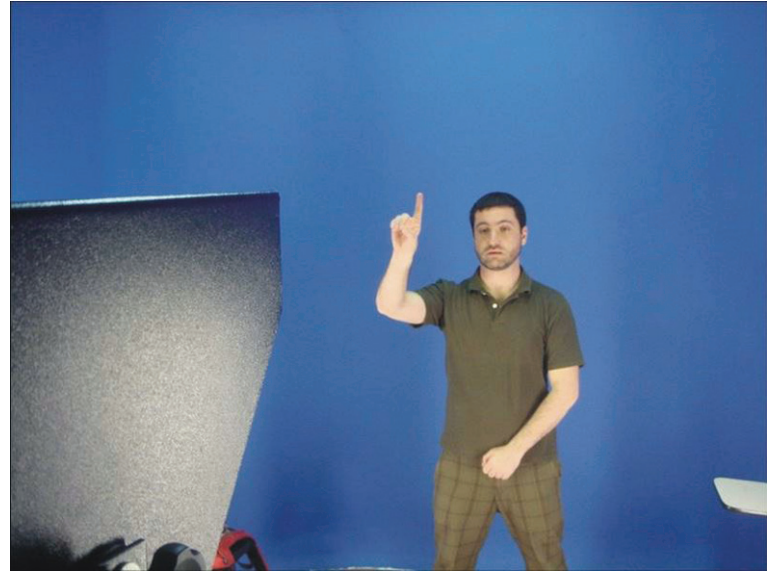

Figura 2. Tradutor/ator Rimar Segalla em estúdio com fundo infinito

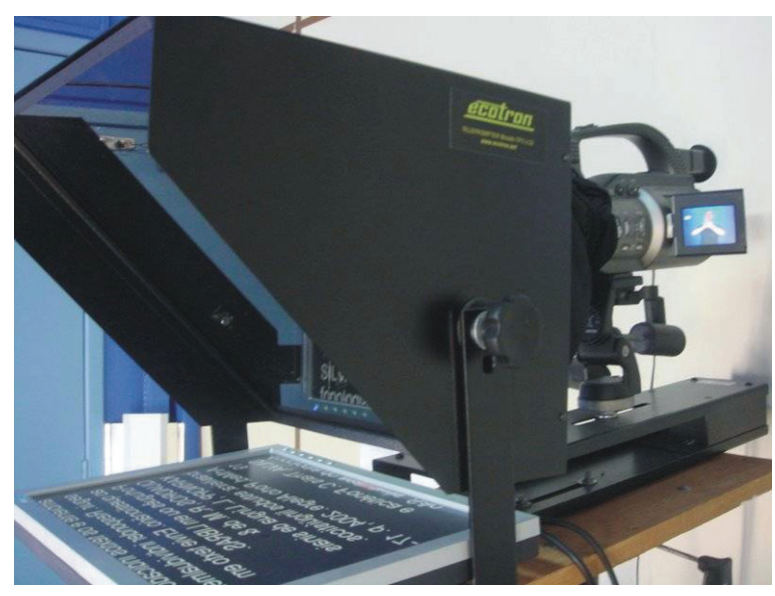

Figura 3. Teleprompter

A equipe de tradução do Curso Letras-Libras contou com a participação de diferentes tradutores surdos desde que foi instituída em 2006, inclusive tendo recebido profissionais de diferentes estados (SC, RJ, SP, AM, CE, RS, GO) que contribuíram e continuam contribuindo através de assessorias via ferramentas de interação virtual, para a ampliação do sinalário ${ }^{4}$ de forma fecunda e diversificada. Essa variedade

4 Sinalário: conjunto de expressões que compõe o léxico de uma determinada língua de sinais. (STUMPF, 2005, p. 36). 
de informantes é relevante para a constituição de repertório lexicográfico em Libras, visto que, por questões históricas - poucos registros ou mesmo ausência de interações entre comunidades surdas de diferentes regiões do país - é comum encontrar diferentes realizações de sinais para um mesmo conceito. ${ }^{5}$

No período de 2009 a 2011, no qual se intensificaram as discussões e desenvolvimento do Glossário a equipe era composta por 6 tradutores surdos - 2 tradutores de português escrito para Libras, 1 tradutor de Libras para Escrita de Sinais e 1 tradutora de ambas as categorias - 1 revisora, 2 cinegrafistas, 1 editor e o coordenador de equipe.

Sendo esta equipe responsável pela tradução de todos os materiais do curso, tais como: textos-base de cada disciplina, provas, atividades, etc. Além dos materiais pedagógicos toda comunicação entre a coordenação geral é realizada em Libras, sendo assim, editais, regimento, informações complementares e o próprio exame de vestibular também eram traduzidos do português escrito para Libras.

Já os tradutores de Escrita de Sinais eram responsáveis pela tradução dos títulos e subtítulos do hipertexto, com objetivo de familiarizar os estudantes com esta forma de registro, complementado o processo de aprendizagem realizado em disciplinas específicas. No Glossário, priorizou-se a tradução das unidades léxicas especializadas, visto que algumas provas também passaram a apresentar versões em Escrita de Sinais ao invés da língua portuguesa escrita. Para preparação da tradução, o tradutor recebe o texto base da disciplina, em língua portuguesa, em meio impresso e digital,

5 Com o desenvolvimento de tecnologias para produção e compartilhamento de vídeos através da internet, as comunidades surdas ampliaram sua possibilidades de interação e conhecimento das variações regionais existentes na língua de sinais brasileira. após a leitura do material para compreensão do conteúdo iniciam-se as pesquisas lexicográfico-terminológicas. Tais pesquisas consistem em consulta a dicionários em língua portuguesa com termos técnicos da área, contato com professores autores, professores ministrantes, monitores, pesquisadores, colegas tradutores, entre outros. Neste momento de preparação o tradutor identifica termos que não possuem correspondentes em Libras ou ainda que considere relevantes para o entendimento do conteúdo. O professor também pode recomendar a inclusão de verbetes no Glossário. Os termos são discutidos nos encontros semanais da equipe e todos participam da composição da paráfrase ${ }^{6}$, além de, sempre que possível, da criação de novos sinais.

$\mathrm{O}$ arquivo digital inicialmente recebido em Word é convertido para extensão .txt, pois este é o formato reconhecido pelo teleprompter (TP). Neste texto que será exibido no TP, o tradutor pode incluir registros que funcionem como lembretes para o momento da tradução, ou mesmo reescrever todo o texto utilizando a estrutura da Língua de Sinais. Conforme observaram os pesquisadores Quadros \& Souza (2008):

Assim, há a necessidade de "ler o texto na estrutura da Língua de Sinais com palavras do Português", ou seja, fazer uso de uma interlíngua escrita, uma espécie de "glosa" em Português do texto na Língua de Sinais, para apoiar a memória da tradução sinalizada.

\footnotetext{
6 "Um enunciado A é denominado paráfrase de um enunciado $B$ se $A$ contém a mesma informação que $B$. As frases podem ser paráfrases uma da outra porque contêm sinônimos ou porque diferem estruturalmente em formas que não afetam o significado. Pode-se, também, dizer que a frase passiva é a paráfrase da frase ativa correspondente. Mais correntemente, chama-se paráfrase ao desenvolvimento explicativo de uma unidade ou de um texto. [Fonte: DUBOIS et al. (1973)]". (Dicionário de Termos Linguísticos da Associação de Informação Terminológica. Disponível em http://www.ait.pt/index2. htm?http://www.ait.pt/recursos/dic_term_ling/index.htm)
} 
Desse modo, os tradutores/surdos fazem a leitura (ou o estudo) do texto em Português. Depois disso, utilizam essa interlíngua escrita com base naquilo que ficou compreendido e apreendido da leitura prévia do conteúdo, já pensando na estrutura do texto a ser traduzido na Língua de Sinais. Por fim, eles tomam por base esse produto interlinguístico - as "glosas" - para encenarem sua versão em Libras (QUADROS \& SOUZA, 2008, p. 188-9).

\section{0 glossário letras-libras como fer- ramenta de apoio a aprendizagem}

Segundo dicionário Houaiss, o glossário era utilizado na Idade Média e Renascença continha um conjunto de termos de uma área do conhecimento e seus significados. Localizava-se na parte final de um manuscrito, ou era enfeixado num volume próprio, de anotações interlineares (glosas), sobre o sentido de palavras antigas, termos técnicos ou sentidos poucos conhecidos encontrados nos textos da obra. Também servindo como elucidário.

No curso Letras-Libras, o glossário é utilizado como elucidário para termos técnicos ou cujos sentidos são poucos conhecidos dentro da comunidade Surda.

No ambiente virtual de aprendizagem são disponibilizados os textos necessários para a formação dos estudantes do curso Letras-Libras. Por se tratar de textos repletos de conceitos que devem ser entendidos, aprendidos e aplicados ao longo do curso, frequentemente encontram-se termos técnicos na língua portuguesa escrita que (ainda) não possuem correspondentes em Libras.

Os verbetes são traduzidos em Libras e Escrita de Sinais e constituem-se em ferramenta de apoio no processo de formação dos futuros Professores de Libras Surdos e Intérpre- tes de Libras. Ao mesmo tempo, favorecem a ampliação do conhecimento acerca do ensino de libras e da tradução de verbetes da língua portuguesa para a língua de sinais de acordo com o contexto de cada disciplina.

Além disso, o Glossário Letras-Libras visa contribuir com a ampliação do sinalário de Libras. Sendo relevante não só para estudantes do curso, mas também para tradutores/intérpretes de modo geral e pesquisadores da área. Como destacou a pesquisadora Faria-do-Nascimento (2009):

Conscientizar estudantes surdos, de cursos de graduação, a respeito dos processos de construção terminológica permitirá o enriquecimento ainda mais acelerado da LSB, e a rápida sistematização e divulgação dos neologismos terminológicos acarretará o acesso e o domínio mais rápido, também dos intérpretes para adequarem sua tradução ao contexto emergente (FARIA-NASCIMENTO, 2009, p. 55).

No entanto, apesar de as novas tecnologias favorecerem o desenvolvimento de repertórios lexicográficos, ainda são relativamente poucas as iniciativas de elaboração de repertórios para áreas de especialidade. Destacam-se nesse campo além do Glossário Letras-Libras, os trabalhos desenvolvidos pela FENEIS do Rio Grande do Sul com o Fórum de Estudos Surdos na Área de Informática - FESAI ; do Projeto Glossário Científico em Língua Brasileira de Sinais, idealizado e produzido pelo Instituto de Bioquímica Médica da Universidade Federal do Rio de Janeiro sob coordenação da professora Vivian Rumjanek"; do Projeto "Sinalizando a Física" da Universidade Federal do Mato Gros-

\footnotetext{
7 Para mais informações ver: http://www.feneis.org.br/rs/fesai/

${ }^{8}$ Alguns vídeos dos DVDs produzidos nesse projeto podem ser visualizados no youtube.
} 
so ${ }^{9}$; do blog Terminologia da Política Brasileira em LIBRAS/Língua Portuguesa organizado pelo pesquisador e tradutor José Ednilson Júnior ${ }^{10}$; do blog WebSurdo com sinais da área de informática produzido pelo tradutor e pesquisador Francinei Rocha Costa ${ }^{11}$; do Guia FotoLibras coordenado por Tatiana Martins ${ }^{12}$; do Glossário de Amamentação em Libras produzido pelas Secretarias de Saúde e Educação do Mato Grosso do Sul ${ }^{13}$; além dos vocabulários elaborados em trabalhos acadêmicos como no caso de Faria-do-Nascimento (2009) e Amorim (2012).

Mesmo em Língua de Sinais Americana que vem sendo investigada sistematicamente desde 1960 é mais comum encontrar repertórios lexicográficos de língua geral do que em áreas de especialidade.

Oliveira e Weininger (2012) atribuem a necessidade de desenvolvimento de repertórios de áreas de especialidade em Libras às questões históricas de dificuldades de aprendizagem da língua portuguesa descrita por vários pesquisadores surdos brasileiros. Conforme atestado em SILVA (2009):

Em muitos casos, o surdo lê, mas não entende o que lê, não consegue construir o sentido do texto, tem o costume de ler as palavras isoladamente, sem considerar seu contexto, costuma sempre buscar a tradução para a língua de sinais. O fracasso da leitura pela maioria dos surdos, por muitos anos, pode estar ligado a fatores como: (1) prática pedagógica em que o professor segue o caminho mais fácil ensinando palavra por palavra e descartando os elementos de ligação como preposições, conjunções e artigos, pois deduzem que a língua de sinais não possui estes

9 Ver: http://www.ufmt.br/sinop/sinaisdafisica/trabalhos/vocmecimp.pdf

10 Ver: http://politicaemlibras.blogspot.com.br/

11 Ver: http://gepid.upf.br/websurdo/

12 http://www.fotolibras.org/pdf/guia_fotolibras_total.pdf

13 http://www.saude.ms.gov.br/controle/ShowFile. php?id=115652 conectores; (2) grande maioria dos professores que ensinam a língua portuguesa para surdos não são fluentes na língua de sinais, o que acarreta um grande barreira na mediação entre professor e aluno, além da descaracterização da Libras como língua efetiva, e, por último, (3) o fato de os surdos estarem diante de textos em português e não em Libras (SILVA, 2009, p. 50).

\subsection{Metodologia de desenvolvimen- to do glossário letras-libras}

Desde 2010, a equipe do Glossário deixou de fazer parte do conjunto de tarefas da equipe de tradução, embora ainda conte com a participação de todos os membros da primeira equipe. A equipe tornou-se independente com espaço e momento próprios para discussões e pesquisas, e assessoria direta de professores convidados. Além dos tradutores surdos, participam da equipe:

- As coordenadoras do grupo professoras Marianne Stumpf e Janine Oliveira.

- O coordenador da equipe de tradução;

- A revisora;

- Um dos cinegrafistas, aluno do curso Letras-Libras presencial;

- Um bolsista do curso de graduação presencial exclusivo da equipe de glossário realizando pesquisa, assessoria aos programadores e adaptação de novas ferramentas de Escrita de Sinais;

- Um bolsista do curso de graduação em Ciência da Computação desenvolvedor do Novo Glossário Letras-Libras;

- Uma estudante de mestrado em Design e Expressão Gráfica - pesquisadora de "Diretrizes de interfaces interativas aplicadas a Glossários para LIBRAS", responsável pelo novo layout do Glossário. 
- Um estudante de doutorado em Engenharia e Gestão do Conhecimento pesquisador de "Desenvolvimento de Conteúdo em Línguas de Sinais para Ambientes Digitais" consultor do Novo Glossário Letras-Libras, em especial na ferramenta de busca com base nos códigos da Escrita de Sinais;

- O professor doutor Markus Weininger, do programa de pós-graduação em Estudos da Tradução (PGET-UFSC), oferecendo suporte teórico específico em conceitos da Linguística e estratégias de tradução.

Nas reuniões semanais são discutidos os verbetes selecionados pelos tradutores. Em geral, o tradutor já apresenta resultados de pesquisa realizada com representantes de comunidades surdas de todo o Brasil. O grupo também realiza consultas a dicionários que são referências na área, tais como, Dicionário Enciclopédico Ilustrado Trilíngue, de Fernando Capovilla, Dicionário da Língua Brasileira de Sinais do Instituto Nacional de Educação de Surdos, Comunicação em Língua de Sinais Internacional, Dicionário de Informática em LIBRAS do FESAI - Fórum de Estudos Surdos na Área de Informática; dicionários de Língua de Sinais Americana (ASL) e Língua de Sinais Francesa (LSF) disponíveis na internet, além de dicionários de Lingüística e Tradução e os já conhecidos Aurélio, Houaiss, Michaelis, entre outros. Também são realizadas pesquisas através do Cyber Café, espaço reservado para comunicação entre estudantes do Curso Letras-Libras, solicitando-se a colaboração dos estudantes para conhecer os sinais utilizados nos estados em que estão sediados os pólos do curso.

Cada termo apresentado nos vídeos do Glossário (Figura 4) apresenta a seguinte estrutura:
- Soletração da palavra.

- Sinal a ser utilizado pelos tradutores do curso.

- Explicação do termo.

- Exemplos.

- Variações regionais.

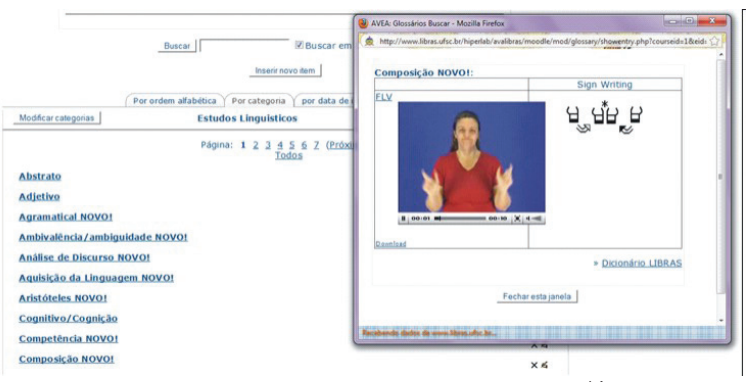

Figura 4. Glossário Letras-Libras ${ }^{14}$

Caso a equipe não conheça um 'sinal' em Libras que corresponda ao termo em português e, ainda não seja possível apresentar uma proposta de neologismo para o termo, o Glossário tem a seguinte apresentação:

- Soletração da palavra.

- Explicação do termo.

- Exemplos.

Sendo a soletração um recurso utilizado como espécie de 'empréstimo' enquanto não existe um 'sinal' considerado adequado para representar o conceito estudado. Esta prática é comum em outras línguas de sinais como se pode comprovar na citação abaixo de pesquisadores de Língua de Sinais Americana.

Technical terms are fingerspelled only if no sign currently exists and the English term is important to know. However, a combination of signs may be enough to carry the concept until a more efficient sign is created by the

\footnotetext{
$\overline{{ }^{14} \mathrm{Na} \text { janela imagem }}$ da tradutora Heloíse Gripp Diniz.
} 
Deaf community (TENNANT; BROWN, 1998, p. 20$).^{15}$

A construção deste sinalário tem se mostrado enriquecedora para ampliação do léxico de Libras, de forma responsável e comprometida. Isso se evidencia com as frequentes solicitações de intérpretes em todo país que desejam ter acesso a este material, também estudantes surdos, pesquisadores e até mesmo instituições que desejam oferecer cursos semelhantes e ter acesso ao conhecimento desenvolvido pela equipe UFSC para avançar ainda mais nas conquistas da área.

Sendo assim, a proposta atual objetiva intensificar as discussões e construir o Glossário em ambiente independente, embora permaneça sempre vinculado ao curso Letras-Libras por constituir-se em ferramenta de/para aprendizagem dos estudantes. O ambiente independente se deve ao desejo de possibilitar o acesso de outros usuários, não só os estudantes matriculados no curso, expandindo o conhecimento que está sendo construído pela equipe.

\section{Recursos tecnológicos}

O curso Letras-Libras funciona na plataforma moodle, um ambiente virtual de aprendizagem (Figura 5) utilizado por educadores em diversos países por ser uma ferramenta on-line gratuita, com vários recursos e constante atualização.

\footnotetext{
15 Os termos técnicos são soletrados somente se não existe um sinal corrente e é importante saber o termo em Inglês. No entanto, uma combinação de sinais pode ser suficiente para representar o conceito até que um sinal mais eficiente seja criado pela comunidade surda.
}

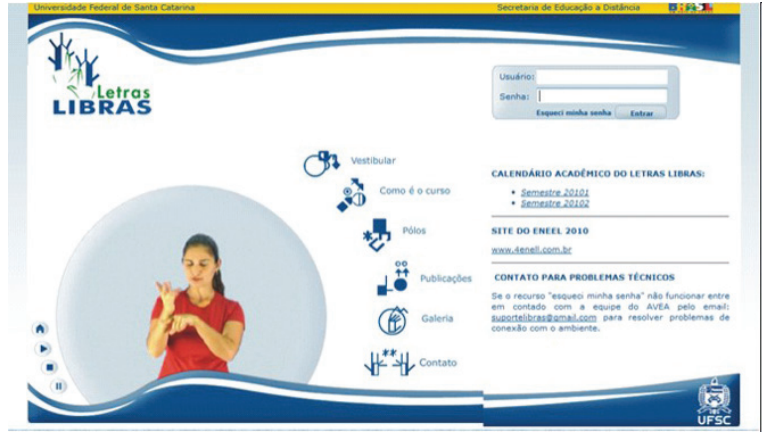

Figura 5. Página inicial do curso Letras-Libras

No ambiente virtual adaptado para a comunidade surda são exploradas todas as possibilidades de acesso e valorização da informação visual, utilizando-se vídeos em Libras, textos escritos em português, textos em Escrita de Sinais para a composição de hipermídias e links (Figura 6).

A plataforma moodle apresenta layout inicial padrão para inserção prioritariamente de texto, possibilitando também inserção de imagens. A equipe de programadores e designers do Hiperlab precisou fazer adaptações para inserção de vídeos e links com imagens, textos ou mesmo outros vídeos. Além disso, o curso Letras-Libras precisou adquirir um servidor de grande capacidade para armazenar os dados dos materiais produzidos para disciplinas, bem como as atividades postadas pelos alunos. ${ }^{16}$

\footnotetext{
16 Sobre o desenvolvimento do ambiente virtual do curso Letras-Libras ver: RIBAS, Armando Cardoso. A interface do ambiente virtual de ensino-aprendizagem do curso letras-libras segundo as características da cultura surda e os critérios de usabilidade. [Dissertação de Mestrado]. Universidade Federal de Santa Catarina, Centro de Comunicação e Expressão. Programa de Pós-Graduação em Design e Expressão Visual, Florianópolis, 2008; e SILVA, Mônica Renneberg da. Contribuições do design para a evolução do hiperlivro do AVEA-LIBRAS: o processo de desenvolvimento de interfaces para objetos de aprendizagem. [Dissertação de Mestrado]. Universidade Federal de Santa Catarina, Centro de Comunicação e Expressão, Programa de Pós-Graduação em Design e Expressão Gráfica, Florianópolis, 2010.
} 


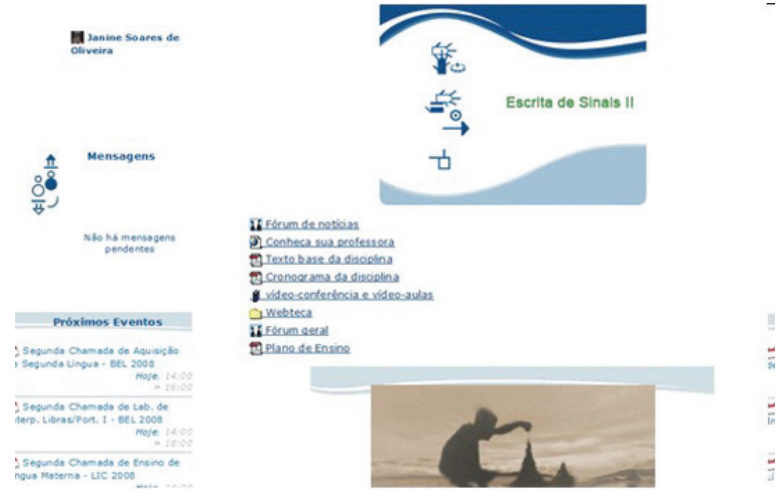

Figura 6. Página da disciplina Escrita de Sinais II

Nesse contexto, o Novo Glossário Letras-Libras já está sendo desenvolvido com objetivo de ampliar o Glossário para disponibilizá-lo (on-line e em página independente) a toda comunidade acadêmica interessada. Além disso, serão implementadas novas ferramentas de busca baseadas nos parâmetros ${ }^{17}$ de Libras e não só na busca por ordem alfabética em português já consolidada em materiais semeIhantes, mas que não satisfaz plenamente as necessidades dos estudantes surdos.

O projeto de atualização do Glossário também inclui filtros de buscas baseados nos símbolos da Escrita de Sinais e, a partir destes, o uso de avatares. ${ }^{18} \mathrm{O}$ ideal de visual em tecnologia seria utilizar o avatar em libras, porém, ainda é difícil encontrar uma tradução automática que atenda às especificidades da língua de sinais.

Nesse campo de investigação destacam-se as pesquisas desenvolvidas pelo Projeto $\mathrm{SiSi}$

\footnotetext{
17 Assim como nas línguas orais são identificadas nas línguas de sinais, particularmente, em Libras, unidades mínimas distintivas para formação de sinais. Os principais aspectos ou parâmetros fonológicos de Libras são: configuração de mão, locação e movimento. Para mais detalhes ver Ferreira-Brito (1995, 1993, 1990) e Quadros (2004).

${ }^{18}$ Avatar é um editor gráfico de sinais, apresentado no monitor do computador e apoiado por um personagem gráfico articulado.
}

(Say It Sign It) da IBM ${ }^{19}$; pelo GTI Graphics Group $^{20}$ da Universidade Pompeu Fabra; pela Unicamp sob coordenação do professor José Mario De Martino. ${ }^{21}$

\section{Escrita de sinais}

A Escrita de Sinais é um sistema visual de registro das línguas de sinais. Os símbolos utilizados nesta escrita buscam expressar os movimentos, as formas das mãos, as expressões não-manuais e os pontos de articulação. Assim, as Línguas de Sinais contam com registros em vídeo e em Escrita de Sinais. O curso Letras-Libras utiliza estes dois recursos aliado a imagens e animações para melhor atender aos estudantes surdos.

Além da tradução dos títulos e subtítulos do hipertexto, alguns vídeos têm seu conteúdo completo traduzido para Escrita de Sinais (Figura 5). No entanto, na nova versão do glossário optou-se por apresentar-se somente o 'sinal' propriamente dito em Escrita de Sinais. Esta mudança ocorreu por sugestão dos próprios estudantes do curso que fizeram uso das ferramentas de interatividade disponibilizadas pela coordenação do curso para envio de sugestões, elogios e críticas.

\footnotetext{
${ }_{19}$ Ver: http://mqtt.org/projects/sisi

${ }^{20}$ Ver: http://gti.upf.edu/automatic-sign-language-avatar-for-video-news/

${ }^{21}$ Ver: http://www.dca.fee.unicamp.br/ wmamaral/sistema/ index.html
} 


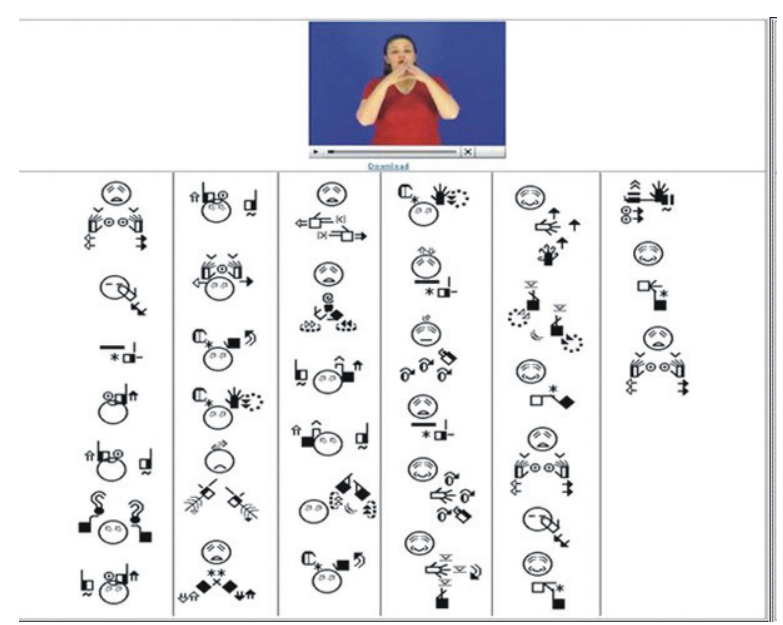

Figura 7. Glossário. Termo: Abstrato

Como proposta, em médio prazo, serão inseridas também as variações regionais dos termos apresentados no Glossário utilizando cores diferenciadas que serão associadas às diferentes regiões do Brasil. No momento, estas variações regionais são apresentadas em vídeo pelos tradutores, logo após a apresentação do conceito dos termos.

\section{Considerações finais}

A Equipe de Tradução se consolidou durante a oferta das primeiras turmas do curso Letras-Libras produzindo materiais de relevância para a educação de surdos, dentre estes, destacou-se nesse artigo o Glossário Letras-Libras. O Glossário constituiu-se em importante ferramenta na formação dos estudantes, na atua- ção de tradutores/intérpretes e principalmente na valorização e ampliação do léxico de Libras.

Para isso a equipe conta sempre com a contribuição de pesquisadores da área com envio de sugestões para enriquecer o sinalário do curso Letras-Libras. Além das contribuições terminológicas para área de linguística, a equipe UFSC também tem sido procurada por pesquisadores de outras instituições que atuam no desenvolvimento de repertórios lexicográficos em diferentes áreas de especialidade para trabalhar em conjunto a partir do conhecimento construído no curso Letras-Libras. Trabalha-se para consolidar essa parceria de elaboração e disponibilização de "glossários em Libras" para várias áreas de especialidade apoiada no software que vem sendo desenvolvido na UFSC para armazenamento e busca de sinais em banco de dados terminológico.

O conhecimento construído pela equipe de Glossário constitui-se em ferramenta de consulta que contribui para a melhor qualidade das aulas de graduação e pós-graduação, pesquisas na área de língua de sinais, uso da $\mathrm{Co}^{-}$ munidade surda, congressos, etc.

Além disso, comprova que a Libras é língua plena e viva, que se amplia com a necessidade de representar termos técnicos. É um upgrade que acontece na comunidade surda, até pouco tempo limitada a um nível muito abaixo da capacidade de seus integrantes, expandindo rapidamente sua língua através de acesso a oportunidades que sempre foram seu direito e hoje começam a se tornar realidade. 


\section{Referências}

AMORIM, Gildete da S. Sinalizando e Incluindo: na saúde, realidade ou ilusão? [Dissertação de Mestrado]. Niterói, RJ: Centro Universitário Plínio Leite, 2012.

FARIA-NASCIMENTO, Sandra Patrícia de. Representações Lexicais da Língua de Sinais Brasileira. Uma proposta lexicográfica. [Tese de doutorado] Brasília: Universidade de Brasília. Instituto de Letras. Departamento de Linguística, Português e Línguas Clássicas, 2009.

HOUAISS, Antônio. VILLAR, Mauro de Salles. Dicionário Houaiss da Língua Portuguesa. 1 Vol. Rio de Janeiro: Objetiva, 2001.

OLIVEIRA, Janine S. de. WEININGER, Markus J. Elaborating an On-line Multi-Access, Multi-Modal Brazilian Sign-Language Glossary for Technical Terms in Linguistics. In: Sign Language Interpretation and Translation Studies in Brazil. Washington, DC: Gallaudet University Press, 2012.

QUADROS, Ronice Müller de. Karnopp, Lodenir. Língua de Sinais Brasileira: Estudos Lingüísticos. Porto Alegre: Artes Médicas. 2004

. CERNY, Roseli Zen, PEREIRA, Alice Theresinha Cybis. Inclusão de surdos no ensino superior por meio do uso da tecnologia. In: QUADROS, Ronice Müller de (Org.). Estudos Surdos III, Petrópolis, RJ: Arara Azul, 2008, p. 32-57.

SOUZA, Saulo Xavier. Aspectos da tradução/encenação na Língua de Sinais Brasileira para um ambiente virtual de ensino: práticas tradutórias do curso de Letras Libras. In: QUADROS, Ronice Müller de (Org.). Estudos Surdos III. Petrópolis, RJ: Arara Azul, 2008, p. 170-209.

SILVA, Fábio Irineu da. Analisando o processo de leitura de uma possível escrita da língua brasileira de sinais: Signwriting. [Dissertação de Mestrado] Florianópolis: Universidade Federal de Santa Catarina. Programa de pós-graduação em Educação, 2009.

STUMPF, Marianne Rossi. Aprendizagem de Escrita de Língua de Sinais pelo Sistema Signwriting: Línguas de Sinais no papel e no computador. [Tese de doutorado]. Porto Alegre: Universidade Federal do Rio Grande do Sul. Faculdade de Educação. Programa de pós-graduação em Informática na Educação, 2005.

TENNANT, Richard A.; BROWN, Marianne Gluszak. The American Sign Language hand-shape Dictionary. Washington DC: Gallaudet University Press, 1998.

universidade federal de SANTA CATARinA. Projeto Pedagógico do Curso de Licenciatura em Letras Libras. Florianópolis: UFSC, 2006 
Submetido para avaliação em 25 de junho de 2010.

Aprovado para publicação em 02 de agosto de 2013.

Janine Soares Oliveira: Doutoranda do Programa de Pós-Graduação em Estudos da Tradução do Centro de Comunicação Expressão da Universidade Federal de Santa Catarina - Florianópolis-SC - Brasil.

E-mail: janinemat@gmail.com

Marianne Rossi Stumpf: Doutora em Informática na Educação e coordenadora do Curso Letras Libras EaD da Universidade Federal de Santa Catarina - Florianópolis-SC - Brasil.

E-mail: marianne@ead.ufsc.br 